Neal, T.M.S., PytlikZillig, L.M., Bornstein, B.B., \& Shockley, E. (2016). Inspiring and advancing the many-disciplined study of institutional trust. In E. Shockley, T.M.S. Neal, B.H. Bornstein, \& L.M. PytlikZillig (Eds.), Interdisciplinary perspectives on trust: Towards theoretical and methodological integration (pp. 1-16). NY: Springer.

This is a pre-print version of chapter cited above. It is not the publication of record. Please see the Springer book or the individual chapters through the Springer website for the final versions of record: http://www.springer.com/us/book/9783319222608 


\title{
Inspiring and Advancing the Many-Disciplined Study of Institutional Trust
}

Tess M. S. Neal, ${ }^{\mathrm{a}, \mathrm{b}, \dagger}$ Lisa M. PytlikZillig, ${ }^{\mathrm{b} \dagger}$ Brian H. Bornstein, ${ }^{\mathrm{c}}$ Ellie Shockley ${ }^{\mathrm{b}}$

${ }^{\text {a }}$ Corresponding author, Interdisciplinary College of Arts \& Sciences, Arizona State University, Phoenix, AZ 85069 USA, tess.m.s.neal@gmail.com

${ }^{\mathrm{b}}$ University of Nebraska Public Policy Center, Lincoln, NE 68588-0228 USA

${ }^{c}$ Department of Psychology, University of Nebraska-Lincoln, Lincoln, NE 68588 USA

${ }^{\dagger}$ The first two authors contributed equally to this chapter.

\begin{abstract}
The purpose of this volume is to consider how trust research, particularly trust in institutions, might benefit from increased inter- or transdisciplinarity. In this introductory chapter, we first give some background on prior disciplinary, multidisciplinary, and interdisciplinary work relating to trust. Next, we describe how this many-disciplined volume on institutional trust emerged from the joint activities of the Nebraska Symposium on Motivation and a National Science Foundation-funded Workshop on institutional trust. This chapter describes some of the themes that emerged, while also providing an overview of the rest of the volume, which includes chapters that discuss conceptualizations, definitions, and measurement of trust; institutional trust across domains and contexts; and theoretical advances regarding the "dark" and "light" sides of institutional trust. Finally, we conclude with some thoughts about the future of and potential promises and pitfalls of trust as a focus of interdisciplinary study.
\end{abstract}


Chapter 1 of the Workshop Volume (INTRO)

\title{
Keywords
}

Words/phrases in parentheses are not keywords, but words/phrases in text that should also be linked in the text by the keyword.

\author{
context(s) (of trust) \\ culture \\ interdisciplinary (interdisciplinarity) \\ multidisciplinary (multidisciplinarity) \\ transdisciplinary (transdisciplinarity) \\ measurement \\ philosophy of science (philosopher of science) \\ Symposium on Motivation (Symposium) \\ Workshop
}


Trust in institutions is widely touted as critical to effective governance, successful business operations, efficient legal systems, and, in general, optimal functioning of institutions and social systems (e.g., Bornstein \& Tomkins, 2015; Gibson, Caldeira, \& Spence, 2005; Ostrom \& Walker, 2003; Tyler \& Fagan, 2008). It is, therefore, no wonder that trust and trust-related issues are investigated within disciplines ranging from psychology, sociology, and economics, to management, government, law, and policy studies. Indeed, contributors to this volume identify themselves as scholars from each of these disciplines, as well as political science, criminal justice, finance, business, public health, organizational behavior, developmental studies, environmental science, and public administration. Accordingly, a large number of both discipline-specific (e.g., Journal of Personality and Social Psychology, American Political Science Review, Academy of Management Review) and general or multidisciplinary journals (e.g., Science, American Behavioral Scientist, Law and Society Review) publish research on institutional trust.

Most of the research on trust in institutions has been conducted within individual disciplines rather than integratively across research areas. Regarding disciplinarity, philosopher of science Karl Popper (1963) wrote:

Disciplines are distinguished partly for historical reasons and reasons of administrative convenience (such as the organization of teaching and of appointments), and partly because the theories which we construct to solve our problems have a tendency to grow into unified systems. But all this classification and distinction is a comparatively unimportant and superficial affair. We are not students of some subject matter but students of problems. And problems may cut across the borders of any subject matter or discipline (pp. 66-67). 
Research that bridges disciplinary boundaries can take different forms, each with implications for how problems are addressed. For example, the terms multidisciplinary, interdisciplinary, and transdisciplinary have been distinguished by the extent to which different disciplines collaborate and come up with integrative products and solutions regarding a given topic or issue.

Disciplinary research occurs within a single discipline. In multidisciplinary research, multiple disciplines focus on a topic or problem from their unique perspectives — often each focusing on a different aspect of the problem in a way that retains disciplinary separation. Interdisciplinary research is more collaborative, and involves disciplines working together on the same foci. Successful programs of interdisciplinary research sometimes generate transdisciplinary perspectives in which concepts and theories from different disciplines are blended into an overarching framework and in which the salience of the original disciplinary boundaries is largely eliminated (adams \& Light, 2014; Rosenfield, 1992). According to these distinctions, multidisciplinary work is additive across disciplines; interdisciplinary work is interactive; and transdisciplinary work is integrative - and potentially transformative (Ellis, 2008; Mitchell, 2005; Pennington, Simpson, McConnell, Fair, \& Baker, 2013). "Many-disciplined” is a term used by Light and adams (in press) to refer simultaneously to all three of these variations of how disciplines might work together.

Benefits of interdisciplinary and transdisciplinary research include their potential to produce uniquely innovative and consequential science, both in terms of theoretical breakthroughs and long-term solutions to applied problems, as well as in cross-discipline citations, a sign of highly generative research programs (Brint, Marcey, \& Shaw, 2008; Ellis, 2008; National Academy of Sciences, 2005; Rosenfield, 1992; Shi, Adamic, Tseng, \& Clarkson, 2009). Transdisciplinary research may lead to new constructs, methods, frameworks, and 
practical applications. The aims of such integrative science are to more rapidly produce solutions to pressing public health and scientific issues (Boyack, Klavans, \& Börner, 2005; Manton, Gu, Lowrimore, Ullian, \& Tolley, 2009). Sometimes — as in the case of the merging of physics, chemistry and biology into molecular biology — entire new fields of study are created and sustained (Sewell, 1989). Farming systems research is another example of successful transdisciplinarity. Such research sprang from the collaborative work of agronomists, anthropologists, and economists, and resulted in theoretical advances, provision of solutions to practical problems such as farming technology diffusion (or lack thereof), and eventually became institutionalized as a field of study in its own right (Rosenfield, 1992).

As Light and adams (in press) argue, interdisciplinarity is a dynamic - rather than static state. To test their hypothesis, they conducted a bibliographic network study of HIV/AIDS research and found that some subtopics became increasingly interdisciplinary (e.g., vaccine development), whereas others moved in the opposite direction and became increasingly segmented into disconnected disciplinary domains over time (e.g., drug resistance). They also described how some fields that began as a discipline became multi- or interdisciplinary (e.g., social sciences of religion), whereas other fields - such as demography, environmental studies, and American studies - evolved into their own disciplines after beginning as interdisciplinary topics of study. Thus, knowledge production crosses boundaries over time, may come from within or across disciplines, and can move from disciplinarity to various forms of manydisciplined production and vice-versa over time. Based on theory and empirical findings, Light and adams developed the Dynamic Multidimensional Model of Knowledge Production to reflect this dynamic state of how knowledge develops over time.

Although proponents of interdisciplinary research tend to argue that moving from 
modular disciplinary studies toward inter- and transdisciplinary research is almost invariably beneficial (Klein, 1990; National Academy of Sciences, 2005), recent theoretical contributions to the science of interdisciplinarity suggest that disciplinarity has strengths of its own (adams \& Light, 2014; Jacobs, 2014; Jacobs \& Frickel, 2009; Light \& adams, in press). Those who defend the importance of disciplinary science argue that disciplines provide an effective social organization for knowledge production and that massively disrupting the structure of the scientific community might not live up to the lofty goals of interdisciplinarity (Light \& adams, in press). Shifting resources and reorganizing universities to prioritize interdisciplinarity may actually disrupt the efficient progress of knowledge production in some cases. That is, increasing interdisciplinarity may be beneficial in many cases, but in others, increasing modularity or disciplinarity may actually be more beneficial in terms of efficiently solving pressing societal problems. Thus, it may be useful to heed the suggestion issued by Light and adams (in press), that an oversimplified focus on interdisciplinarity as a promising solution for solving big problems should be expanded to the more theoretically useful question of "What patterns of disciplinary boundary crossing allow for more efficient problem solving?” (p. 15). Perhaps someday sophisticated science will allow us to recognize when questions require interdisciplinarity versus focused disciplinary research to solve a given problem efficiently. In the meantime, encouraging simultaneous interdisciplinary and disciplinary research to address problems seems to be the most promising approach.

With this caveat in mind, the present volume considers whether successful interdisciplinary research on trust in institutions is necessary to do justice to the complexity of the topic and the issues relevant to institutional trust (Cheng, Henisz, Roth, \& Swaminathan, 2009). For example, the transdisciplinary (and transnational) study of trust more generally might 
help us understand how to build public institutions that many different groups in the Middle East would see as legitimate and trustworthy in order to generate sustained peace (Ramsbotham \& Wennmann, 2014). It might help us reduce the health and wealth disparities in the United States and many other countries (Boulware, Cooper, Ratner, LaVeist, \& Powe, 2003; Dovidio et al., 2008; Halbert, Armstrong, Gandy, \& Shaker, 2006; O'Malley, Sheppard, Schwartz, \& Mandelblatt, 2004; Thompson, Valdimarsdottir, Winkel, Jandorf, \& Redd, 2004). And it might help us come up with new solutions for reducing crime and violence and bolstering well-being throughout the world (Messner, Baumer, \& Rosenfeld, 2004; Putnam, 1995, 2000).

For those of us who see the potential value of interdisciplinarity in trust scholarship, and who want to try to do it, how should we do so? Some have noted that interesting and worthwhile problems like those listed above are necessary for inspiring transdisciplinary and transformative research (Pennington et al., 2013). Such meaningful problems may facilitate interdisciplinarity by attracting and inspiring individuals and groups of researchers to exhibit the patience that also is touted as essential for interdisciplinary success (Maton, Perkins, \& Saegert, 2006; Rosenfield, 1992). Patience is indeed required if Rosenfield is correct that, for transdisciplinarity to emerge from interdisciplinarity, it requires more than just collaborations between scholars from different disciplines. According to Rosenfield (1992),

Each team member needs to become sufficiently familiar with the concepts and approaches of his and her colleagues as to blur the disciplinary bounds and enable the team to focus on the problem as part of broader phenomena: as this happens, discipline authorization fades in importance, and the problem and its context guide an appropriately broader and deeper analysis (p. 1344).

Some scholars propose that certain "design principles" may help to foster interdisciplinarity. 
Recommendations include creating a collaborative and diverse team with members of varied competencies and roles; developing a common language and joint understanding of the problem(s) under investigation, research questions, and criteria for success; designing a common methodological framework; engaging in continuous formative evaluation and adjustment; anticipating and mitigating conflict; and taking steps to enhance and support interests and capabilities needed to participate over time (Lang et al., 2012). Others suggest that transformative ideas coming from interdisciplinary research will be facilitated by encountering disorienting dilemmas that lead to critical reflection, reflective discourse, and, ultimately, new mental models (Pennington et al., 2013).

The present volume is the result of a workshop designed to explore the potential benefits of advancing the many-disciplined study of institutional trust. The contributors to this volume participated in a workshop designed to introduce their work to one another and generate collaborations between scholars studying institutional trust from different disciplines. Our hope was to facilitate efforts to transform the relatively disciplinary-specific studies of trust in institutions into an integrative field of study, and to advance a fuller and more comprehensive understanding of trust in institutions - or at least to begin exploring what patterns of disciplinary boundary crossing might be beneficial. We were especially interested in clarifying trust research by continuing and building on prior efforts to sort through what has been termed a "conceptual morass" (Barber, 1983, p. 1) and a "quagmire” (Metlay, 1999, p. 100) of past trust research. Thus, before discussing our Workshop methods in greater detail, we first give an overview of some prior integrative efforts that provided a starting point for our efforts.

\section{Prior Advances in the Many-Disciplined Study of Trust}

Although there does not exist a great deal of interdisciplinary and transdisciplinary 
research on trust, ours is not the first attempt to integrate scholarship on trust or trust in institutions from across disciplines. For instance, in Trust in Organizations: Frontiers of Theory and Research, Kramer and Tyler (1996) offered an important effort at bringing together a crossdisciplinary collection of scholars from the fields of psychology, economics, sociology, and organizational research. Their volume assembled cutting-edge conceptual perspectives and methodological approaches within trust scholarship. Authors tackled topics such as the antecedents of trust, the impact of social structures and organizations on trust, and the consequences of trust for organizational functioning.

Several many-disciplined efforts have been ambitious enough to generate books. For instance, in 1995 the Russell Sage Foundation launched a decade-long Trust Initiative (see http://www.russellsage.org/research/trust). This program sought to clarify the nature of trust across a variety of social relationships, including friendship, professional relationships, relationships between organizations, and the relationship citizens have with institutions. The Initiative asked for theoretical and methodological answers to questions about the sources of trust, what trust means for markets and democracy, to what extent trust between individuals resembles trust between an individual and an institution, and what determines when trust is harmful. The initiative also encouraged work discriminating between rival theories of trust. Scholars from the fields of political science and sociology led the Initiative, hosting conferences and bringing in additional scholars from philosophy, history, economics, and psychology. These efforts resulted in about two dozen books on trust across varying contexts and cultures.

Ostrom and Walker's (2003) book, for example, Trust and Reciprocity: Interdisciplinary Lessons from Experimental Research, resulted from the Russell Sage Foundation Trust Initiative. While this volume focused largely on experimental research and was situated in behavioral 
economics, authors included political scientists, sociologists, psychologists, and an animal behaviorist as well. It leveraged these disciplinary perspectives to address deep social scientific questions, such as the seeming paradox of prosocial behavior. The book helped address questions such as why humans trust each other enough to become vulnerable and to make decisions that lead to better shared social outcomes, despite the vulnerability to exploitation inherent in prosocial choices.

Other efforts of integrating trust scholarship have been narrower in their scope. Namely, some efforts at integrating trust scholarship across multiple disciplines have focused specifically on trust conceptualizations, resulting in the cataloguing of the types of conceptualizations and definitions of trust used across disciplines, the illumination of their commonalities and differences, and the proposal of frameworks that might adequately capture and organize such commonality and variation in theoretically and empirically useful ways (e.g., Castelfranchi \& Falcone, 2010; Earle, Siegrist, \& Gutscher, 2007; Rousseau, Sitkin, Burt, \& Camerer, 1998), as discussed in more detail in Chapter 2 of this volume. Other efforts have focused on trust across contexts, or methodological approaches and issues. For example, focusing on situations in which trust occurs, Li (2014) delved into trust literatures and developed a generalized taxonomy of contexts to be applied across disciplines, and then applied the taxonomy to five articles by organizational, psychological, and political scholars in the same journal issue. Meanwhile, handbooks on methods have long brought together methods for the study of trust across disciplines, and they continue to be published, reflecting the best practices of the day (e.g., Bachmann \& Zaheer, 2006, 2013; Lyon, Möllering, \& Saunders, 2012, in press).

\section{A Multidisciplinary Symposium and an Interdisciplinary Workshop}

To build on these prior efforts, we gathered together leading junior and senior trust 
scholars, representing a variety of disciplines, in a single venue - a National Science Foundation (NSF)-funded meeting entitled "Institutional Trust and Confidence: An Interdisciplinary Workshop." The Workshop was held at the University of Nebraska-Lincoln on April 26 and 27, 2014, in conjunction with the $62^{\text {nd }}$ Annual Nebraska Symposium on Motivation (NSM), titled "Cooperation and Compliance with Authority: The Role of Institutional Trust," held April 24 and 25, 2014 (Bornstein \& Tomkins, 2015).

To encourage interdisciplinary thinking prior to the Workshop, we asked pre-registered Workshop participants to complete a pre-Workshop survey in which they rank-ordered a set of ten topics that could be discussed in breakout sessions, and to add new ideas for topics they thought were important to include in the Workshop discussions. These topics included the differences among multi-, inter- and transdisciplinary research; defining and conceptualizing trust; differences and disagreements between theories and models; the importance of contexts, cultures, and domains; distinctions between "light and dark" (i.e., advantageous or positive versus disadvantageous or negative) aspects of trust; and questions for the future. The ranking task was rather informally constructed and primarily intended to (1) get participants thinking about useful directions for interdisciplinary work, and (2) give those of us organizing the Workshop some idea of the interests of the participants.

Most Workshop participants joined us for the talks and discussions held as part of the motivation Symposium. On the first day of the Symposium, they were exposed to in-depth discussions of the relationships among legitimacy, procedural justice, trust, and cooperation from a faculty member in a sociology department (Hegtvedt, 2015), a faculty member in a criminology department (Jackson, 2015), a political scientist (Gibson, 2015), and a sociologist who studies these issues in court settings (Rottman, 2015). On the second day, they heard about 
the impact of political polarization on institutional trust (Theiss-Morse, Barton, \& Wagner, 2015), factors influencing trust in experts (MacCoun, 2015), when trust matters the most in management and organizational contexts ( $\mathrm{Li}, 2015)$, and about disciplinary and contextual differences in the meanings and uses of trust (Schoorman, Wood, \& Breuer, 2015).

During the two days of the NSF Workshop that followed the motivation Symposium, participants engaged in in-person discussions, presentations, panels, and debates about the topics they were asked to generate and rank-order prior to the Workshop. "Data /theory blitz" sessions featured short presentations on topics ranging from the development of trust and legal socialization of adolescents, the moral foundations of trust, and the relationship between trust and calculativeness to trust in healthcare and international financial institutions and issues surrounding the measurement and methods used in trust research. "Coffee klatsch" sessions provided informal opportunities for participants to discuss how their research disciplines overlapped, as well as mentoring opportunities for newer trust scholars interacting with established scholars (bringing relatively junior and more senior scholars together was a key goal of the Workshop).

Themed sessions featured presentations and discussions about topics such as trust in policy-relevant science, legitimacy of elected versus appointed officials, theories of procedural justice, and trust in healthcare contexts. In line with the idea of fostering interdisciplinarity through focus on "important and worthwhile" practical problems, a special 90-minute themed session involved a panel discussion focused on real-world trust applications. The panelists included people in positions of institutional power in the real world who were interested in the practical applications of research on institutional trust. Panelists asked and answered questions from the trust researchers in the audience, and they shared their thoughts about what questions 
institutional trust researchers might consider studying. Panelists included the Mayor of the City of Lincoln and his Chief of Staff, the director of the Nebraska Department of Natural Resources, a Nebraska senatorial legislative aide, the Associate Chief of Medicine at the regional Veterans Administration Hospital, two sitting appellate judges from different state courts (Kansas Court of Appeals and the Nebraska Supreme Court), and a magistrate judge from the U.S. District Court for the District of Maryland (a trial-level, federal court).

In summary, throughout the Workshop, participants were encouraged to form collaborative cross-disciplinary relationships, synthesize cohesive and comprehensive interdisciplinary theories of trust, generate solutions for important theoretical and methodological questions facing trust scholars across disciplines, and answer overarching questions not specific to any particular domain of expertise. Next we describe the topics that came to the forefront during those discussions and that became part of this volume.

\section{Topics, Themes, and Chapters}

A number of the topics that were ranked highly in the pre-Workshop survey became central themes of discussion during both the Symposium and the Workshop. Based on these discussions, the book is organized into three sections: Definitions and Conceptualizations, Domains and Contexts, and Light and Dark Aspects of Trust.

\section{Definitions and Conceptualizations}

The topic receiving the highest average ranking in the pre-Workshop survey was definitions and conceptualizations. This topic included defining differences and similarities between trust and trust-related constructs, and discussion of "what barriers and remaining issues need to be resolved to achieve consensus on terminology and taxonomy? Is such a consensus even desirable? Do we need a single definition? How should we conceptualize and measure 
trust?” Building on points of discussion raised during both the Symposium (e.g., Li, 2015; Schoorman et al., 2015) and the Workshop, the current volume contains a number of chapters that give substantial attention to definitions and conceptualizations of trust.

For example, in Chapter 2, PytlikZillig and Kimbrough - researchers from the fields of social psychology and law ${ }^{1}$ - review past work from numerous fields that has catalogued different trust conceptualizations and definitions, identified their commonalities and differences, and suggested integrative frameworks or models as solutions. They argue that "trust-as-process" approaches to conceptualizing and defining trust offer a number of benefits, including representing current usages of the term and retaining the multiplicity of constructs important to a full understanding of trust. They suggest that trust-as-process approaches to definitional issues could be furthered if future conceptual work focused in more depth on differences between definitions of other psychological constructs - such as dispositions, evaluations, expectations, intentions, and behaviors. In so doing, the field might further clarify a "set" of trust-relevant definitions that future researchers could use to help clarify and classify the part(s) of the trust process on which their own research focuses.

In Chapter 3, Jackson and Gau - researchers in criminology and criminal justice - define trust and differentiate it from legitimacy in the context of public attitudes toward police. Jackson and Gau assert that trust and legitimacy are related concepts and that the definitions of each are somewhat unclear and overlapping. They attempt to separate them by arguing that trust is the positive expectations that the public has about the way representatives of an institution (e.g., police officers) should behave, whereas legitimacy is about public recognition and justification of the rightful power of an institution. Institutional trust and legitimacy overlap when people judge the appropriateness of institutions of legal authority on the basis of the appropriate police 
use of power.

In Chapter 4, Uslaner - a political scientist - focuses on the broadest definition of trust: what does trust really mean? What are the sources of trust, and is it stable over time? These questions lead him to consider important distinctions like trust in people we know versus trust in strangers, strategic versus moral considerations in trusting others, and interpersonal as opposed to institutional trust (especially trust in the government). He also discusses the relationships between trust and inequality and between trust and faith. Ultimately, he concludes that trust is worthy of attention precisely because its scope is so broad.

In Chapter 5, Hamm and Hoffman - representing psychology, statistics, criminal justice, and environmental science perspectives - focus on the conceptualization and measurement of trust. They consider how the overlapping nature of various related trust-like constructs has contributed to the "conceptual morass" of the study of trust. Although Structural Equation Modeling (SEM) was developed as a tool to help clarify the relationships among related constructs, Hamm and Hoffman show how SEM can be difficult for trust researchers to use due to the covariance associated with highly correlated trust-relevant constructs. They describe the pros and cons of various strategies for using SEM to study such a difficult construct as trust, and they demonstrate with an example from a real study how trust researchers can best use SEM. Specifically, they recommend and demonstrate how research with strongly-correlated latent constructs should test a higher-order factors alternative model to predict the covariance among the latent factors. Doing so, they conclude, addresses the problems that arise from working with excessive covariance while preserving the theoretical and statistical utility of the lower-order factors to test hypothesized relationships with various trust-relevant outcomes.

\section{Domains and Contexts}


The second most highly ranked topic on the pre-Workshop survey was about whether and how trust differed across domains and contexts. Participants who discussed this topic in depth through various Workshop activities and beyond focused on differences between interpersonal and institutional trust, differences in trust across disciplinary domains, the nature of trust across cultural domains, and trust in policy-relevant science.

For example, in Chapter 6, Campos-Castillo, Woodson, Theiss-Morse, Sacks, FleigPalmer, and Peek focus in depth on the definition of "institutional" as it is used as part of the construct of "institutional trust." These researchers span the fields of sociology, political science, management, and medicine. They point out that most of the trust literature focuses on interpersonal trust (i.e., trust between individuals), and that although some research has focused on institutional trust, these latter studies have assumed a shared consensus exists for what constitutes an institution. Ultimately, persons comprise institutions. Their chapter examines the evidence concerning the reciprocal relationship between interpersonal and institutional trust by describing in detail how these relationships emerge in the political arena and in healthcare contexts. They point out that many of the studies of "institutional trust" actually seem to be about interpersonal trust regarding those people involved in the institutions, as the analyses revolve around interactions with these authorities. Studies of trust in which people are asked to focus on the institution rather than any interpersonal issues are less common - and therefore more needed, according to the authors of this chapter.

In Chapter 7, Herian and Neal - researchers from political science, psychology, and public policy - focus on trust as a multilevel phenomenon and present a three-level organizing framework for conceptualizing trust between trustors and trustees. The levels include person (one individual), group (relatively small set of identifiable people), and institution (formal or 
informal system, organization, or mechanism of social order). They provide a $3 \times 3$ matrix of the relationships between each of these levels to ground their discussion of trust at each level. Herian and Neal argue that the differences between each of these levels have implications for justifiable distinctions in methodological approaches across different settings and contexts. Dovetailing with the content covered by Campos-Castillo et al. (Chapter 6), Herian and Neal assert that much of the trust literature to date has been unclear about the level at which trust has been conceptualized and measured - partially due to the overlap and confusion between interpersonal and institutional trust. They suggest that trust research will be facilitated across disciplines if researchers are more careful about specifying and aligning their levels of conceptualization and measurement in future work.

In Chapter 8, Hamm, Lee, Trinkner, Wingrove, Leben, and Breuer-a group of researchers spanning the fields of criminal justice, psychology, law, organizational behavior, public administration, management, and environmental science-examine conceptualizations of trust in four domains: public administration, the police, the state courts, and medicine. They identify key words that are used to conceptualize trust in these institutions, finding commonalities and differences but concluding that trust is generally conceptualized as "willingness to be vulnerable" across these domains. In addition, most of the domains feature similar consequences of trust (e.g., compliance, cooperation). They note the largest differences between domains in antecedents, with performance especially important to trust in public administration, procedural justice to trust in the police, fairness to trust in the courts, and trustor factors (such as demographics and access to health care) to trust in medicine. As they note, although the specific antecedents differ, they have in common that they decrease felt vulnerability or increase the acceptability of vulnerability. 
In Chapter 9, Cole and Cohn - both social psychologists - address the importance of understanding linguistic, cultural, and colloquial definitions of trust within trust scholarship. Such understanding may help to address questions surrounding inconsistent and even contradictory findings within scholarship on institutional trust. In their chapter, they examine the philosophical issues surrounding cross-cultural conceptualizations of trust, discuss intra-cultural and interdisciplinary divergence in conceptualizations of institutional trust, and detail past crossnational findings to illustrate some of the knowledge of trust across different cultures. They also examine data collected through a cross-national study conducted shortly after the democratic movement in Europe. In doing so, they compare Western European and Eastern European countries to understand the predictors of trusting the highest court in the country, illustrating the importance of cross-cultural research within trust scholarship.

\section{"Dark" and "Light" Aspects of Trust}

The third-ranked topic on the pre-Workshop survey was titled "dark and light sides of trust." Discussions of this topic focused on the optimistically biased nature of the trust literature - that many researchers seem to assume that trust is a good thing. Conversely, conventional descriptions of lack of trust — distrust, mistrust—often seem to imply that an absence of trust is negative. But there are downsides to trust, as well as potential benefits to distrust.

Chapter 10 was written by Neal, Shockley, and Schilke - researchers from the fields of psychology, law, sociology, and management. They review theories and empirical research to reveal implications for a "dark side" of institutional trust, suggesting a "Goldilocks principle" of institutional trust where too little and too much trust can be problematic. Although trust researchers (especially institutional trust researchers) appear to focus on the positive aspects of trust, excessive trust can be problematic for people by leaving them susceptible to manipulation 
and exploitation. Neal et al. describe in depth different processes by which excessive trust may develop: external processes (actions taken by institutions that generate public trust), internal processes (intrapersonal factors that increase a trustor's level of trust independent of the actions of the institution), and intersecting external-internal processes (when institutions leverage knowledge of how internal processes work to effect increases in trust). They draw upon research from organizational, legal, governmental, and political systems to demonstrate the dark side of too-high trust in various contexts. They conclude with a call for more research on these issues and for greater researcher sensitivity to the ethical nuances of studying institutional trust.

In Chapter 11, Shockley and Shepherd (from the fields of social psychology and marketing) discuss in depth one facet of an "internal process" of the dark side of individuals' trust in institutions: compensatory institutional trust. They review and integrate major theories and evidence to describe how people's trust in institutions can be generated to satisfy people's internal needs for feeling safe and secure and for seeing the world as an orderly and predictable place. Specifically, when people experience a threat to their safety, security, sense of meaning, or understanding of the world, they may be motivated to increase their trust in external powerful institutions. This process, independent of any trustworthy or even untrustworthy actions taken by the institutions, is theorized to reduce the anxiety associated with such internal threats. Shockley and Shepherd present specific examples from the literature showing how this "hydraulic" process works. They end the chapter by encouraging scholars of institutional trust to consider the relevance of compensatory trust processes to their work.

\section{Concluding Chapter}

The final chapter of the book, written by Tom Tyler - one of the most well-known scholars of institutional trust and related issues such as procedural justice and legitimacy - offers 
his perspectives on the contributions this volume makes to the interdisciplinary study of institutional trust.

\section{Where Do We Go From Here?}

The refinement in conceptualizing trust achieved by this Workshop volume has important societal implications. In the context of policymaking and politics, the lack of trust in government has been lamented by all sides of all aisles, and elected and appointed officials are actively seeking (without, as yet, much success; see Theiss-Morse, Barton, \& Wagner, 2015) to regain the public's trust in governmental institutions. In business organizations, enhancing trust is viewed as a basis for productivity and corporate well-being. Trust-related research such as the study of procedural justice has been used regularly by law enforcement agencies and courts in the U.S. and beyond to inform and change structures and practices. As the chapters on the dark side of trust illustrate, blindly increasing trust is not always desirable. Nonetheless, in light of the steady decline in trust in others as well as in institutions (Twenge, Campbell, \& Carter, 2014), the benefits of increasing trust, at least in the current time (2015) and place (U.S. and potentially elsewhere), and doing so through substantive and legitimate means (rather than simply trying to increase perceptions of trust without actually behaving in more trustworthy ways), clearly seem to outweigh the costs.

The focus of the present volume has been not so much on how to increase trust, but on how best to conceptualize and study trust, especially trust in institutions. It is much more challenging to enhance trust when there is little agreement on its antecedents, meaning(s), and consequences. In terms of trust scholarship, then, what are the most pressing next steps? Where do we go from here?

The main answer to this question that arises from the present work, as well as much 
related scholarship on trust (e.g., Bornstein \& Tomkins, 2015), is "more interdisciplinarity." We generally agree with this answer, but an oversimplified focus on interdisciplinarity has limited utility (Light \& adams, in press). Interdisciplinary research is not always necessary to do justice to a research field, even one as complex as institutional trust (Cheng et al., 2009). Rather, the situation is considerably more subtle and complex. It would be better to ask, "What patterns of disciplinary boundary crossing allow for more efficient, effective, and translatable trust research?" For those of us studying trust in institutions from a variety of disciplines, we need to think about when collaborating across disciplines makes sense and when specializing in depth on narrower questions with strong disciplinary tools, methods, and techniques makes sense in its own right.

Relatively well developed areas, such as trust in the courts (e.g., Gibson, 2015; Rottman, 2015 ) trust in law enforcement (e.g., Jackson, 2015; Jackson \& Gau, this volume), and trust in management and organizational settings (e.g., McEvily \& Tortoriello, 2011) may be ripe candidates for interdisciplinary and even transdisciplinary research; whereas newer areas, such as public administration and e-commerce (e.g., Hamm et al., this volume; McKnight, Choudhury, \& Kacmar, 2002), might benefit more from first laying a strong disciplinary foundation. But then again, perhaps those more developed areas should become more deeply disciplinary in order to delve further into the specific nuances of their unique contexts and the newer applications of trust research should start with an inter- or transdisciplinary approach to have a relatively comprehensive map of trust to begin with, before getting more specific. Or perhaps both more established and newer research areas should proceed in both directions at once (toward more transdisciplinarity as well as more modular disciplinarity), with an attempt to stay informed with the developments in both directions in case they can build on one another. Further discussions of 


\section{Chapter 1 of the Workshop Volume (INTRO)}

these issues will be useful for all varieties of institutional trust scholars. A better understanding of trust and its development, maintenance, and diminution has the potential to assist society in many different ways. The scholars involved in this volume have already influenced numerous organizations, through their scholarly and applied publications and through their consultancies with public and private organizations. Their contributions to this volume further elevate trust's relevance and usefulness to individuals and organizations across a variety of contexts. 


\section{References}

adams, j., \& Light, R. (2014). Mapping interdisciplinary fields: Efficiencies, gaps and redundancies in HIV/AIDS research. PloS one, 9(12), e115092. Retrieved from http://journals.plos.org/plosone/article?id=10.1371/journal.pone.0115092.

Bachmann, R., \& Zaheer, A. (2006). Handbook of trust research. Cheltenham, UK: Edward Elgar.

Bachmann, R., \& Zaheer, A. (2013). Handbook of advances in trust research. Cheltenham, UK: Edward Elgar.

Barber, B. (1983). The logic and limits of trust. New Brunswick, NJ: Rutgers University Press.

Bornstein, B. H., \& Tomkins, A. J. (Eds.). (2015). Motivating cooperation and compliance with authority: The role of institutional trust (Vol. 62nd Nebraska Symposium on Motivation). New York: Springer.

Boulware, L. E., Cooper, L. A., Ratner, L. E., LaVeist, T. A., \& Powe, N. R. (2003). Race and trust in the health care system. Public Health Reports, 118, 358-365. Retrieved from http://www.jstor.org/stable/4598864.

Boyack, K. W., Klavans, R., \& Börner, K. (2005). Mapping the backbone of science. Scientometrics, 64, 351-374.

Brint, M. E., Marcey, D., \& Shaw, M. C. (2008). Integrated science: New approaches to education: A virtual roundtable discussion. New York: Springer.

Castelfranchi, C., \& Falcone, R. (2010). Trust theory: A socio-cognitive and computational model. Chichester, West Sussex, UK: John Wiley \& Sons.

Cheng, J. L., Henisz, W. J., Roth, K., \& Swaminathan, A. (2009). From the Editors: Advancing interdisciplinary research in the field of international business: Prospects, issues and 
challenges. Journal of International Business Studies, 1070-1074.

Dovidio, J. F., Penner, L. A., Albrecht, T. L., Norton, W. E., Gaertner, S. L., \& Shelton, J. N. (2008). Disparities and distrust: The implications of psychological processes for understanding racial disparities in health and health care. Social Science \& Medicine, 67, 478-486. doi: doi:10.1016/j.socscimed.2008.03.01.

Earle, T. C., Siegrist, M., \& Gutscher, H. (2007). Trust, risk perception and the TCC model of cooperation. In M. Siegrist, T. C. Earle \& H. Gutscher (Eds.), Trust in cooperative risk management: Uncertainty and scepticism in the public mind (pp. 1-49). London: Earthscan Publications.

Ellis, R. J. (2008). "Problems may cut right across the borders": Why we cannot do without interdisciplinarity. In B. Chandramohan \& S. Fallows (Eds.), Interdisciplinary learning and teaching in higher education: Theory and practice (pp. 3-17). New York: Routledge.

Gibson, J. L. (2015). Legitimacy is for losers: The interconnections of institutional legitimacy, performance evaluations, and the symbols of judicial authority. In B. H. Bornstein \& A. J. Tomkins (Eds.), Motivating cooperation and compliance with authority: The role of institutional trust (Vol. 62nd Nebraska Symposium on Motivation, pp. 81-116). New York: Springer.

Gibson, J. L., Caldeira, G. A., \& Spence, L. K. (2005). Why do people accept public policies they oppose? Testing legitimacy theory with a survey-based experiment. Political Research Quarterly, 58, 187-201.

Halbert, C. H., Armstrong, K., Gandy, O. H., \& Shaker, L. (2006). Racial differences in trust in health care providers. Archives of Internal Medicine, 166, 896-901. doi:10.1001/archinte.166.8.896. 
Hegtvedt, K. A. (2015). Creating legitimacy: The interrelated roles of justice and trust. In B. H. Bornstein \& A. J. Tomkins (Eds.), Motivating cooperation and compliance with authority: The role of institutional trust (Vol. 62nd Nebraska Symposium on Motivation, pp. 55-80). New York: Springer.

Jackson, J. (2015). On the dual motivational force of legitimate authority. In B. H. Bornstein \& A. J. Tomkins (Eds.), Motivating cooperation and compliance with authority: The role of institutional trust (Vol. 62nd Nebraska Symposium on Motivation, pp. 145-166). New York: Springer.

Jacobs, J. A. (2014). In defense of disciplines: Interdisciplinarity and specialization in the research university. Chicago, IL: University of Chicago Press.

Jacobs, J. A., \& Frickel, S. (2009). Interdisciplinarity: A critical assessment. Annual Review of Sociology, 35, 43-65.

Klein, J. T. (1990). Interdisciplinarity: History, theory, and practice. Detroit, MI: Wayne State University Press.

Kramer, R. M., \& Tyler, T. R. (Eds.) (1995). Trust in organizations: Frontiers of theory and research. Sage Publications.

Lang, D. J., Wiek, A., Bergmann, M., Stauffacher, M., Martens, P., Moll, P., Swilling, M., \& Thomas, C. J. (2012). Transdisciplinary research in sustainability science: Practice, principles, and challenges. Sustainability Science, 7, 25-43.

Li, P. P. (2014). A tentative typology of context for trust research and beyond. Journal of Trust Research, 4, 83-89.

Li, P. P. (2015). Trust as a leap of hope for transaction value: A two-way street above and beyond trust propensity and expected trustworthiness. In B. H. Bornstein \& A. J. 
Tomkins (Eds.), Motivating cooperation and compliance with authority: The role of institutional trust (Vol. 62nd Nebraska Symposium on Motivation, pp. 37-53). New York: Springer.

Light, R., \& adams, j. (in press). The dynamics of interdisciplinary research processes. In S. Frickel, M. Albert \& B. Prainsack (Eds.), Utopian knowledge? Critical perspectives on interdisciplinary research. New Brunswick, NJ: Rutgers University Press.

Lyon, F., Möllering, G., \& Saunders, M. (2012). Handbook of research methods on trust. Cheltenham, UK: Edward Elgar.

Lyon, F., Möllering, G., \& Saunders, M. (in press). Handbook of research methods on trust, second edition. Cheltenham, UK: Edward Elgar.

MacCoun, R. J. (2015). The epistemic contract: Fostering an appropriate level of putblic trusti n experts. In B. H. Bornstein \& A. J. Tomkins (Eds.), Motivating cooperation and compliance with authority: The role of institutional trust (Vol. 62nd Nebraska Symposium on Motivation, pp. 191-214). New York: Springer.

Manton, K. G., Gu, X.-L., Lowrimore, G., Ullian, A., \& Tolley, H. D. (2009). NIH funding trajectories and their correlations with US health dynamics from 1950 to 2004. Proceedings of the National Academy of Sciences, 106, 10981-10986.

Maton, K. I., Perkins, D. D., \& Saegert, S. (2006). Community psychology at the crossroads: Prospects for interdisciplinary research. American Journal of Community Psychology, $38(1-2), 9-21$.

McEvily, B., \& Tortoriello, M. (2011). Measuring trust in organisational research: Review and recommendations. Journal of Trust Research, 1, 23-63.

McKnight, D. H., Choudhury, V., \& Kacmar, C. (2002). Developing and validating trust 
measures for e-commerce: An integrative typology. Information Systems Research, 13, 334-359.

Messner, S. F., Baumer, E. P., \& Rosenfeld, R. (2004). Dimensions of social capital and rates of criminal homicide. American Sociological Review, 69, 882-903.

Metlay, D. (1999). Institutional trust and confidence: A journey into a conceptual quagmire. In G. T. Cvetkovich \& R. Lofstedt (Eds.), Social trust and the management of risk (pp. 100116). London: Earthscan.

Mitchell, P. H. (2005). What's In A Name?: Multidisciplinary, interdisciplinary, and transdisciplinary. Journal of Professional Nursing, 21, 332-334.

National Academy of Sciences, National Academy of Engineering, Institute of Medicine, Committee on Facilitating Interdisciplinary Research. (2005). Facilitating interdisciplinary research. Washington, DC: National Acadamies Press.

O'Malley, A. S., Sheppard, V. B., Schwartz, M., \& Mandelblatt, J. (2004). The role of trust in use of preventive services among low-income African-American women. Preventive medicine, 38, 777-785. doi: 10.1016/j.ypmed.2004.01.018.

Ostrom, E., \& Walker, J. (Eds.). (2003). Trust and reciprocity: Interdisciplinary lessons for experimental research. Russell Sage Foundation.

Pennington, D. D., Simpson, G. L., McConnell, M. S., Fair, J. M., \& Baker, R. J. (2013). Transdisciplinary research, transformative learning, and transformative science. BioScience, 63, 564-573.

Popper, K. (1963). Conjectures and refutations: The growth of scientific knowledge. London: Routledge.

Putnam, R. D. (1995). Tuning in, tuning out: The strange disappearance of social capital in 
America. PS: Political Science \& Politics, 28, 664-683.

Putnam, R. D. (2000). Bowling alone: The collapse and revival of American community. New York: Simon \& Schuster.

Ramsbotham, A., \& Wennmann, A. (Eds.). (2014). Legitimacy and peace processes: From coercion to consent (Vol. 25). London: Conciliation Resources.

Rosenfield, P. L. (1992). The potential of transdisciplinary research for sustaining and extending linkages between the health and social sciences. Social Science \& Medicine, 35, 13431357.

Rottman, D. B. (2015). Who trusts the trial courts, to what extent, and why? In B. H. Bornstein \& A. J. Tomkins (Eds.), Motivating cooperation and compliance with authority: The role of institutional trust (Vol. 62nd Nebraska Symposium on Motivation, pp. 117-144). New York: Springer.

Rousseau, D. M., Sitkin, S. B., Burt, R. S., \& Camerer, C. (1998). Not so different after all: a cross-discipline view of trust. Academy of Management Review, 23, 393-404.

Schoorman, F. D., Wood, M. M., \& Breuer, C. (2015). Would trust by any other name smell as sweet? Reflections on the meanings and uses of trust across disciplines and context. In B. H. Bornstein \& A. J. Tomkins (Eds.), Motivating cooperation and compliance with authority: The role of institutional trust (Vol. 62nd Nebraska Symposium on Motivation, pp. 13-35). New York: Springer.

Sewell, W. H. (1989). Some reflections on the golden age of interdisciplinary social psychology. Annual Review of Sociology, 15, 1-16.

Shi, X., Adamic, L. A., Tseng, B. L., \& Clarkson, G. S. (2009). The impact of boundary spanning scholarly publications and patents. PloS one, 4, e6547. Retrieved from 
http://journals.plos.org/plosone/article?id=10.1371/journal.pone.0006547\#pone-0006547g006.

Theiss-Morse, E., Barton, D.-G., \& Wagner, M. W. (2015). Political trust in polarized times. In B. H. Bornstein \& A. J. Tomkins (Eds.), Motivating cooperation and compliance with authority: The role of institutional trust (Vol. 62nd Nebraska Symposium on Motivation, pp. 167-190). New York: Springer.

Thompson, H. S., Valdimarsdottir, H. B., Winkel, G., Jandorf, L., \& Redd, W. (2004). The Group-Based Medical Mistrust Scale: Psychometric properties and association with breast cancer screening. Preventive Medicine, 38, 209-218. doi:

10.1016/j.ypmed.2003.09.041.

Twenge, J. M., Campbell, W. K., \& Carter, N. T. (2014). Declines in trust in others and confidence in institutions among American adults and late adolescents, 1972-2012. Psychological Science, 25, 1914-1923.

Tyler, T. R., \& Fagan, J. (2008). Legitimacy and cooperation: Why do people help the police fight crime in their communities? Ohio State Journal of Criminal Law, 6, 231-275. Retrieved from http://ssrn.com/abstract=887737. 
Chapter 1 of the Workshop Volume (INTRO)

\section{Notes}

\footnotetext{
${ }^{1}$ We provide each contributor's field in order to demonstrate how this Workshop and volume integrated multiple disciplinary perspectives. We recognize that researchers' scientific training, departmental affiliation, and personal identification might not always be in perfect alignment; for the sake of simplicity, we rely on contributors' principal academic affiliation (though some have dual appointments).
} 